\title{
Cucumber Phospholipase D alpha gene overexpression in tobacco enhanced drought stress tolerance by regulating stomatal closure and lipid peroxidation
}

Tuo $\mathrm{Ji}^{1 \dagger}$, Shuzhen $\mathrm{Li}^{1 \dagger}$, Lujun $\mathrm{Li}^{1}$, Meili Huang ${ }^{1}$, Xiufeng Wang ${ }^{1,2}$, Min Wei ${ }^{1}$, Qinghua Shi ${ }^{1,2}$, Yan $\mathrm{Li}^{1}$, Biao Gong ${ }^{1}$ and Fengjuan Yang ${ }^{1,2^{*}}$

\begin{abstract}
Background: Plant phospholipase D (PLD), which can hydrolyze membrane phospholipids to produce phosphatidic acid (PA), a secondary signaling molecule, has been proposed to function in diverse plant stress responses. Both PLD and PA play key roles in plant growth, development, and cellular processes. PLD was suggested to mediate the regulation of stomatal movements by abscisic acid (ABA) as a response to water deficit. In this research, we characterized the roles of the cucumber phospholipase D alpha gene (CSPLDa, GenBank accession number EF363796) in the growth and tolerance of transgenic tobacco (Nicotiana tabacum) to drought stress.

Results: The CSPLDa overexpression in tobacco lines correlated with the ABA synthesis and metabolism, regulated the rapid stomatal closure in drought stress, and reduced the water loss. The NtNCED1 expression levels in the transgenic lines and wild type (WT) were sharply up-regulated after 16 days of drought stress compared with those before treatment, and the expression level in the transgenic lines was significantly higher than that in the WT. The NtAOG expression level evidently improved after 8 and 16 days compared with that at 0 day of treatment and was significantly lower in the transgenic lines than in the WT. The ABA content in the transgenic lines was significantly higher than that in the WT. The CSPLDa overexpression could increase the osmolyte content and reduce the ion leakage. The proline, soluble sugar, and soluble protein contents significantly increased. By contrast, the electrolytic leakage and malondialdehyde accumulation in leaves significantly decreased. The shoot and root fresh and dry weights of the overexpression lines significantly increased. These results indicated that a significant correlation between CSPLDa overexpression and improved resistance to water deficit.
\end{abstract}

Conclusions: The plants with overexpressed CSPLDa exhibited lower water loss, higher leaf relative water content, and heavier fresh and dry matter accumulation than the WT. We proposed that CSPLDa was involved in the ABAdependent pathway in mediating the stomatal closure and preventing the elevation of intracellular solute potential.

Keywords: CsPLDa, Transgenic tobacco, Phosphatidic acid, Drought stress, Abscisic acid, Stomatal closure, Lipid peroxidation

\footnotetext{
* Correspondence: beautyyfj@163.com

${ }^{\dagger}$ Tuo Ji and Shuzhen Li contributed equally to this work.

${ }^{1}$ State Key Laboratory of Crop Biology, College of Horticulture Science and

Engineering, Shandong Agricultural University, Tai'an 271018, People's

Republic of China

${ }^{2}$ Key Laboratory of Biology and Genetic Improvement of Horticultural Crops

(Huanghuai Region), Ministry of Agriculture, Tai'an 271018, People's Republic

of China
}

(c) The Author(s). 2018 Open Access This article is distributed under the terms of the Creative Commons Attribution 4.0 International License (http://creativecommons.org/licenses/by/4.0/) which permits unrestricted use, distribution, and reproduction in any medium, provided you give appropriate credit to the original author(s) and the source, provide a link to the Creative Commons license, and indicate if changes were made. The Creative Commons Public Domain Dedication waiver (http://creativecommons.org/publicdomain/zero/1.0/) applies to the data made available in this article, unless otherwise stated. 


\section{Background}

Environmental stresses trigger a wide variety of plant responses, and drought stress is one of the most adverse factors to plant growth and productivity $[1,2]$. Drought stress can increase reactive oxygen species (ROS) generation, increase pyruvic acid content, decrease ascorbic acid content, induce lipid peroxidation injury, and cause irreversible damage, which leads to death [3]. Plants form a complex regulatory mechanism to adapt or resist water deficit during prolonged evolution. Before drought occurs, plants accelerate tissue maturation to effectively avoid damage. Plants develop a strong root system by closing stomata to reduce water loss [4]. External stimuli can be identified by plant cell membranes or osmosensors, leading to the production of secondary messengers that can be transported within the cell [5]. The secondary messengers can adjust the phosphorylation status of downstream proteins by regulating the activity of intracellular protein kinase, invoking the activity of transcription factors, mediating the expression of target genes in the nucleus [6]. These processes affect the plant morphogenesis, transformation of carbon metabolic pathways, hormone synthesis, ROS balance, and osmolyte accumulation, eventually enhancing plant resistance to stress $[7,8]$. When plants sense a drought stress signal, intracellular signaling molecules, such as secondary messengers, are transmitted inside the cell. The signal transduction activates the abscisic acid (ABA)-dependent/ independent pathways, which allow water deficit resistance [9]. At least three ABA-dependent pathways exist in plants, and the transcription factors that regulate these pathways include myeloblastosis, NAC (NAM/ ATAF1/2/CUC2), and others [10, 11]. ABA-independent pathway-related genes mainly include those that possess dehydrating response components in their promoter regions and transcription factors that combine with dehydration-responsive element/C-repeat components [12]. Therefore, differences in ABA accumulation in plants induce different pathways in response to water deficit. Most of the genes related to ABA synthesis and degradation pathways including ZEP/ABA1, NCED, $S D R / A B A 2, L O S 5 / A B A 3, A A O 3 / A B A 5, C Y P 707 A$, and $A O G$, have been cloned and studied [13-15]. One study suggested that the $S D R$ gene is not affected by the drought stress signal [16]. Hence, ABA plays a vital role in the water deficit response mechanism of plants. $\mathrm{ABA}$ participates in the plant response to drought stress by controlling the opening and closing of plant stomata [17, 18]. The stress hormone $\mathrm{ABA}$ and elevated $\mathrm{CO}_{2}$ levels activate complex signaling pathways that are mediated by kinases/phosphatases, secondary messengers, and ion channel regulation in guard cells [19].

Some transcription factor genes respond to drought stress signal, but mainly two kinds of protein participate in the water deficit response: the regulatory and function proteins. The regulatory proteins include protein kinases, transcription factors, and phospholipases. These proteins are involved in the signal transduction of drought stress mainly by adjusting other signaling molecules. The function proteins include the LEA-like protein, molecular chaperones, osmolyte synthetases, transporters, and ROS detoxification protein enzymes. They are directly involved in the drought stress response and repair process [6]. Among these proteins, the plant phospholipase D (PLD) family and the phosphatidic acid (PA) they produce function in drought stress responses [20-23]. PLD exhibits the dual function of membrane degradation and signal transduction [21]. As a lipid-hydrolyzing enzyme, PLD hydrolyzes membrane phospholipids to produce PA and exhibits increased activity under dehydration and hyperosmotic conditions $[24,25]$. The produced PA acts as a secondary messenger, amplifying the signal to possibly mitigate stress injury; thus, it mainly functions in stress injury rather than in membrane degradation in some cases [26]. The detrimental effects of drought stress are prevented by minimizing cuticular water loss and maximizing water uptake [27]. PLD 1 mediates ABA regulation, which controls stomatal closure and decreases transpirational water loss in response to water deficits $[28,29]$. Arabidopsis with abrogated PLD $\alpha 1$ is insensitive to ABA-mediated stomatal closure and exhibits more water loss than that of the wild type (WT) [28], whereas Arabidopsis with overexpressed $P L D \alpha 1$ loses less water than the WT [30]. On one hand, PLD 1 -produced PA binds to ABI1 protein phosphatase $2 \mathrm{C}$, and this interaction may tether ABI1 to the plasma membrane, impede its negative function on ABA response, and enhance ABA-promoted stomatal closure $[28,29]$. On the other hand, $P L D \alpha 1$ interacts with the $G \alpha$ subunit of heterotrimeric $G$ protein to mediate stomatal opening inhibition by ABA $[29,31]$. PA also binds to NADPH oxidase and stimulates its activity to promote ROS or $\mathrm{NO}$ production in ABA-mediated stomatal closure [32]. Additional studies are needed in order to further confirm these results.

Our previous study showed that the cucumber phospholipase D alpha gene (CsPLD $\alpha)$ was involved in the response to hyperosmotic stress, and the overexpression of CsPLD $\alpha$ in tobacco could enhance the tolerance to high salinity, polyethylene glycol and ABA treatments, which was proved in seed germination and seedling condition [33]. Furthermore, the CsPLD $\alpha$-produced PA participated in the salt response by congesting osmolytes, balancing $\mathrm{Na}^{+}-\mathrm{K}^{+}$ratio and eliminating the accumulation of ROS indirectly [34]. In the current study, we found that CSPLD $\alpha$-produced PA could do more work in drought stress response, especially in promoting ABA-mediated stomatal closure, balancing osmolytes, 
and stabilizing the membrane system, which could keep more water in plants. Therefore, these findings suggested that CsPLD $\alpha$ contributed significantly to drought stress in plants.

\section{Results}

NtPLDa1 and NtNAC072 expression under drought stress

To determine the involvement of endogenous NtPLD 1 in drought responses, the NtPLD 1 expression levels in the leaves of the WT and transgenic plants were measured (Fig. 1a). No difference in the NtPLD 1 expression was observed between the WT and transgenic plants before treatment ( 0 day) and after 8 and 16 days of drought stress treatment. However, the expression level of NtNAC072, a drought-induced marker gene, increased after 8 days of treatment and was higher in the transgenic lines than in the WT. The NtNAC072 expression level in the ' $\mathrm{T}_{1}-71$ ' leaves was 2.39 times higher than that in the WT. The NtNAC072 expression level decreased significantly after 16 days $(P<0.05)$ (Fig. 1b). Thus, the CsPLD $\alpha$ overexpression could enhance the sensitivity of plants to drought stress.

\section{CsPLDa mediated the plant response to ABA synthesis and metabolism, stomatal closure, and water loss}

To determine the involvement of CsPLD $\alpha$ in modulating the ABA synthesis and metabolism during water deficit, RT-PCR was conducted to analyze the expression levels of ABA-related genes (Fig. 2), including two key genes in the ABA synthesis and metabolism pathway, namely, NtNCED1 and NtAOG. NtNCED1 is a rate-limiting enzyme in ABA metabolism, whereas NtAOG controls the ABA metabolism. As shown in Fig. 2, the NtNCED1 expression level increased approximately 100 times in all group after 16 days of stress compared with that before treatment, and was significantly higher by $39.8 \%$ in ' $\mathrm{T}_{1}$ 71 ' and $13.5 \%$ in ' $\mathrm{T}_{1}-68$ ' $(P<0.05)$ compared with that in the WT after 16 days of stress (Fig. 2a). The NtAOG expression also evidently enhanced at 8 and 16 days after treatment compared with that at 0 day of treatment, whereas the transgenic lines exhibited a significantly lower expression than that of the WT (Fig. 2b). No difference in NtSDR expression was observed between the transgenic lines and WT at all treatment times (Fig. 2c). The ABA content in the tobacco plants was lower before treatment ( 0 day) and increased almost 30 times at 8 days after the drought stress in both the OE lines and WT. The ABA contents in the leaves of ' $\mathrm{T}_{1}-68$ ' and ' $\mathrm{T}_{1}-71$ ' transgenic plants were significantly higher by 11.2 and $15.5 \%$, respectively $(P<0.01)$. The same significant difference was maintained at 16 days after the water deficit (Fig. 2d).

The role of CsPLD $\alpha$ in the ABA-promoted stomatal closure was also studied (Fig. 3). When the leaves were detached at $0 \mathrm{~min}$, almost $90 \%$ of the stomata were opened in both the OE lines and WT, and the percentages of closed stomata were similar in the OE lines and WT. The dehydration of the detached leaves promoted stomatal closure faster in the $\mathrm{OE}$ lines than that in the WT. The percentages of closed stomata of the ' $\mathrm{T}_{1}-68$ ' and ' $\mathrm{T}_{1}-71$ ' transgenic plants were 41.2 and $51.9 \%$, respectively. The percentage of closed stomata was only $13.4 \%$ in the WT after 10 min of detachment. The percentage of closed stomata increased up to 78.4 and $90.0 \%$ in ' $\mathrm{T}_{1}-68$ ' and ' $\mathrm{T}_{1}-71$ ' at $20 \mathrm{~min}$ of detachment, respectively. Almost no difference between $\mathrm{OE}$ lines was observed at $30 \mathrm{~min}$ of detachment compared to at $20 \mathrm{~min}$ of detachment. However, the percentage of
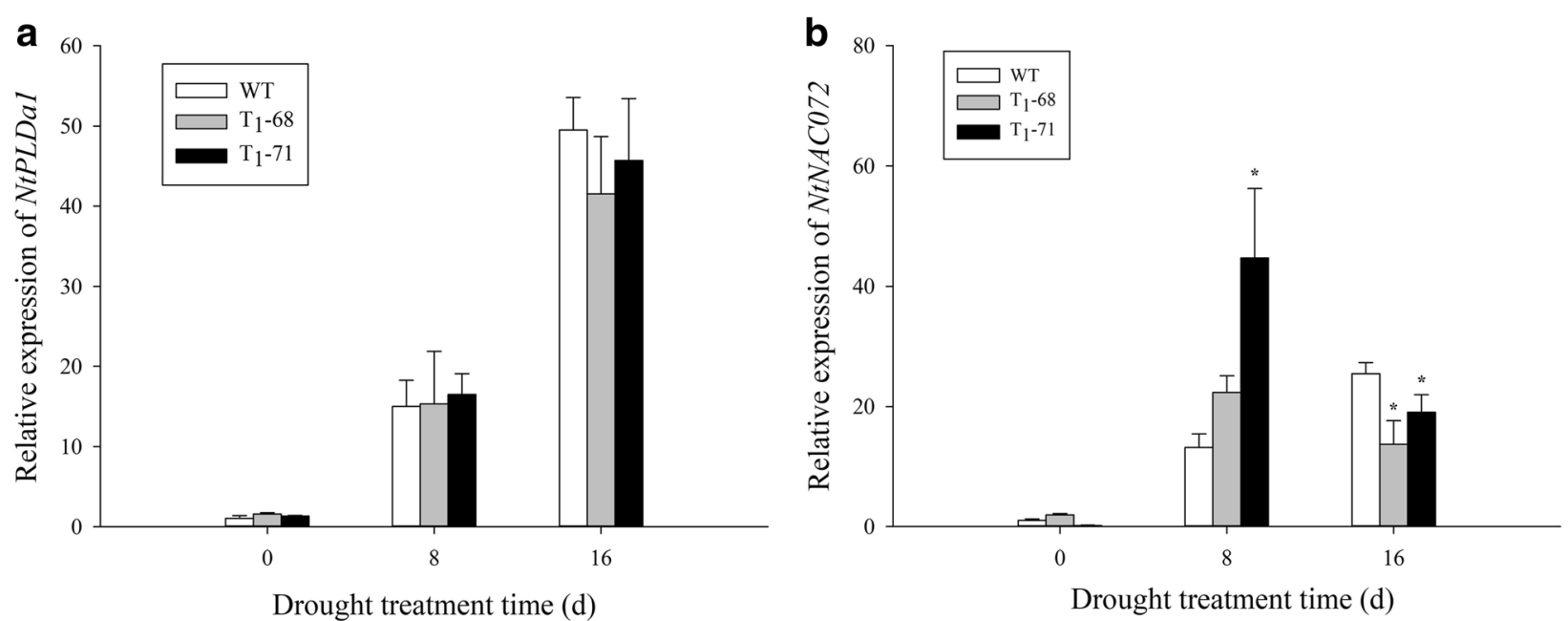

Fig. 1 Effects of drought stress on the expression level of endogenous NtPLDa1(a) and NtNACO72 (b) in leaves of both wild type (WT) and transgenic tobacco after treatment of 0,8 and $16 \mathrm{~d}$. Values are means $\pm \mathrm{SD}(n=3) .{ }^{*}$ and ${ }^{*}$ Significant at $P<0.05$ and $P<0.01$ compared with WT, respectively 

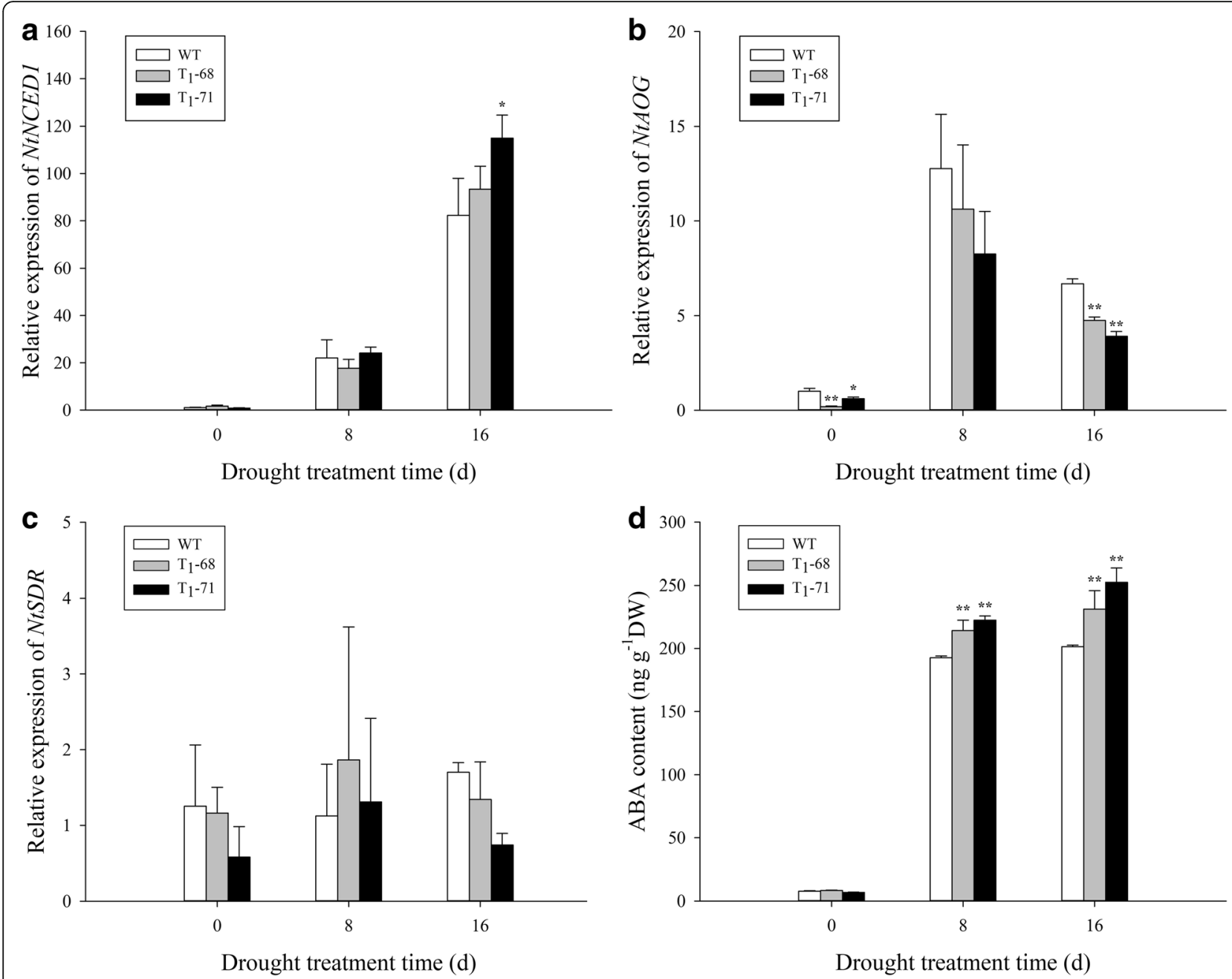

Fig. 2 Effects of drought stress on the relative expression of NtNCED1(a), NtAOG (b), NtSDR (c) and the ABA content (d) in leaves of both wild type (WT) and transgenic tobacco after treatment of 0,8 and $16 \mathrm{~d}$. Values are means $\pm \mathrm{SD}(n=3)$. ${ }^{*}$ and ${ }^{*}$ Significant at $P<0.05$ and $P<0.01$ compared with WT, respectively

closed stomata in the WT was $58.9 \%$ after 30 min of detachment; such increase was faster than that after 20 min of detachment (Fig. 3a). The apertures of the remaining opened stomata were measured, and an evident difference was observed between the OE plants and WT. The stomatal apertures of the ' $\mathrm{T}_{1}-68$ ' and ' $\mathrm{T}_{1}-71$ ' transgenic plants were 3.7 and $3.0 \mu \mathrm{m}$, respectively, but stomatal aperture of the WT was $6.6 \mu \mathrm{m}$ after $10 \mathrm{~min}$ of detachment. The stomatal apertures of ' $\mathrm{T}_{1}-68$ ' and ' $\mathrm{T}_{1}$ 71 ' significantly declined by 2.79 and 3.08 times after $20 \mathrm{~min}$ of detachment compared with those after $0 \mathrm{~min}$ of detachment. The stomatal aperture remained in the WT at $3.0 \mu \mathrm{m}$ (Fig. 3b). The water loss of the ' $\mathrm{T}_{1}-68$ ' and ' $\mathrm{T}_{1}-71$ ' transgenic plants exhibited no obvious difference, but that of the WT was higher than that in the OE lines during $0-8 \mathrm{~h}$ of treatment. After $8 \mathrm{~h}$ of treatment, the water loss of the WT plant was significantly higher by 25.8 and $22.4 \%$ than that of ' $\mathrm{T}_{1}-68$ ' and ' $\mathrm{T}_{1}-$
71', respectively (Fig. 3c). These findings suggested that $C s P L D \alpha$ played an important role in promoting stomatal closure.

\section{FW and DW under drought stress}

As shown in Fig. 4, no significant difference between the transgenic plants and WT was observed under normal conditions $(0 \mathrm{~d})$. A remarkable accumulation of shoots and roots occurred after 8 days of treatment. However, the shoot and root growths of both the WT and transgenic seedlings were severely suppressed after 16 days of exposure to drought stress. In particular, the growth of the WT seedlings was significantly inhibited $(P<0.05)$. The FWs (Fig. 4a) and DWs (Fig. 4b) of the WT, ' $\mathrm{T}_{1}-68$, and ' $\mathrm{T}_{1}-71$ ' shoots at 16 days of treatment were significantly lower by $58.7,41.9$, and $34.8 \%$ and by $34.3,10.0$, and $5.8 \%$, respectively, compared with those at 0 day. The FWs (Fig. 4c) and DWs (Fig. 4d) of the WT, ' $T_{1}-68$ ', 

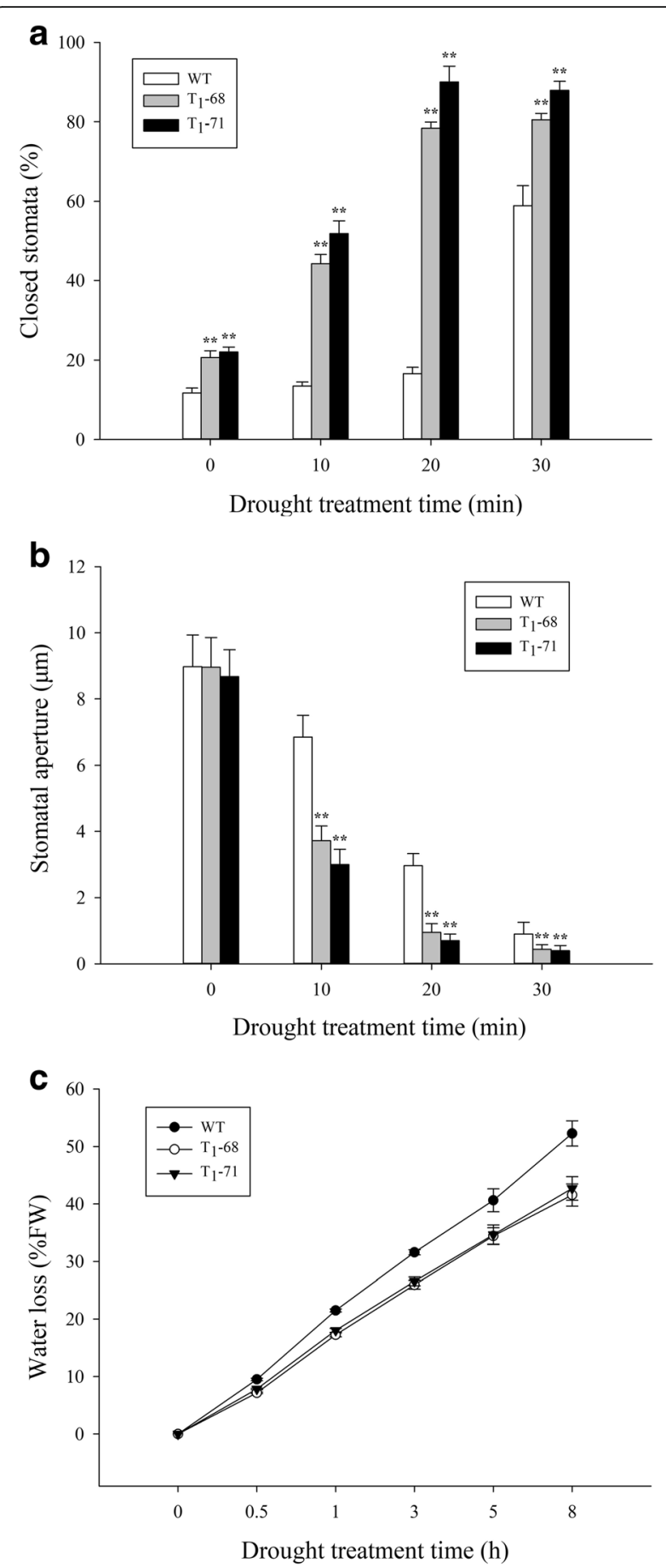

Fig. 3 Effects of drought stress on stomatal closure percentage (a), stomatal aperture (b) after detachment on 0, 10, 20 and 30 min and water loss (c) after detachment on $0,0.5,1,3,5$ and $8 \mathrm{~h}$ in leaves of both wild type (WT) and transgenic tobacco. Values are means \pm SD ( $n=15$ in $(\mathbf{a}, \mathbf{b})$ and $n=3$ in $\mathbf{c}) .{ }^{*}$ and ${ }^{*}$ Significant at $P<0.05$ and $P$ $<0.01$ compared with $W T$, respectively and ' $\mathrm{T}_{1}-71$ ' roots at 16 days of treatment were significantly lower by $69.0,51.8$, and $50.0 \%$ and by $50.5,23.5$, and $19.2 \%$, respectively, compared with those at 0 day. After 16 days of treatment, the shoot FWs and DWs of the ' $\mathrm{T}_{1}-68$ ' transgenic plants increased by 43.1 and $38.6 \%$, respectively, and those of the ' $\mathrm{T}_{1}-71$ ' transgenic plants increased by 59.4 and $42.3 \%$, respectively, compared with those of the WT. After 16 days of treatment, the root FWs and DWs of the ' $T_{1}-68$ ' transgenic plants increased by 63.8 and $63.6 \%$, respectively, and those of the ' $\mathrm{T} 1 \mathrm{1}-71$ ' transgenic plants increased by 70.2 and $70.1 \%$, respectively, compared with those of the WT. Thus, the transgenic tobacco plants exhibited improved drought stress resistance, and CsPLD $\alpha$ may play an important role in alleviating the stress damage caused by heavy drought.

\section{EL and MDA content under drought stress}

Figure 5 shows that under normal conditions ( 0 day), the EL and MDA content of the leaves of the transgenic and WT plants exhibited no significant difference. The EL and MDA content increased compared with those at 0 day with increasing drought time but were significantly lower in the transgenic lines than in the WT $(P<0.05)$. The EL of the WT, ' $\mathrm{T}_{1}-68$ ', and 'T-71' increased by $114.0,62.7$, and $84.5 \%$ and by $168.9,118.9$, and $143.6 \%$ (Fig. $5 \mathrm{a}$ ) after 8 and 16 days of treatment, respectively, compared with those at 0 day of treatment. The MDA content of the WT, ' $\mathrm{T}_{1}-68$ ', and 'T-71' increased by 74.1, 49.9 , and $29.1 \%$ and by $127.0,81.2$, and $62.7 \%$ (Fig. 5 b) after 8 and 16 days of treatment, respectively, compared with those at 0 day of treatment. These results indicated that $C s P L D \alpha$ played an important role in maintaining membrane system stability.

\section{Soluble sugar, proline, and soluble protein contents under drought stress}

There were no significant differences between soluble sugar, proline and soluble protein contents in leaves of the WT and OE lines at 0 day (Fig. 6). While with the increasing of treatment time, the soluble sugar and proline content gradually increased and finally reached the peak after 16 days of treatment. Unlike this, the soluble protein content reached the peak at 8 days, and decreased slightly at 16 days. The soluble sugar content in leaves of WT, ' $\mathrm{T}_{1}-68$ ', and ' $\mathrm{T}_{1}-71$ ' at 16 days increased $8.70,11.08$, and 11.52 times, respectively (Fig. 6a), compared with those at 0 day. The proline content of the ' $\mathrm{T}_{1}-68$ ' and ' $\mathrm{T}_{1}-71$ ' lines increased by $12.6 \%(P<0.05)$ and $18.5 \%(P$ $<0.01$ ), respectively (Fig. $6 \mathrm{~b}$ ), compared with that of WT. After 8 days of treatment, the soluble protein content of the WT, ' $\mathrm{T}_{1}-68$ ', and ' $\mathrm{T}_{1}-71$ ' increased by 30.0 , 43.2, and $45.2 \%$, respectively (Fig. 6c), compared with 

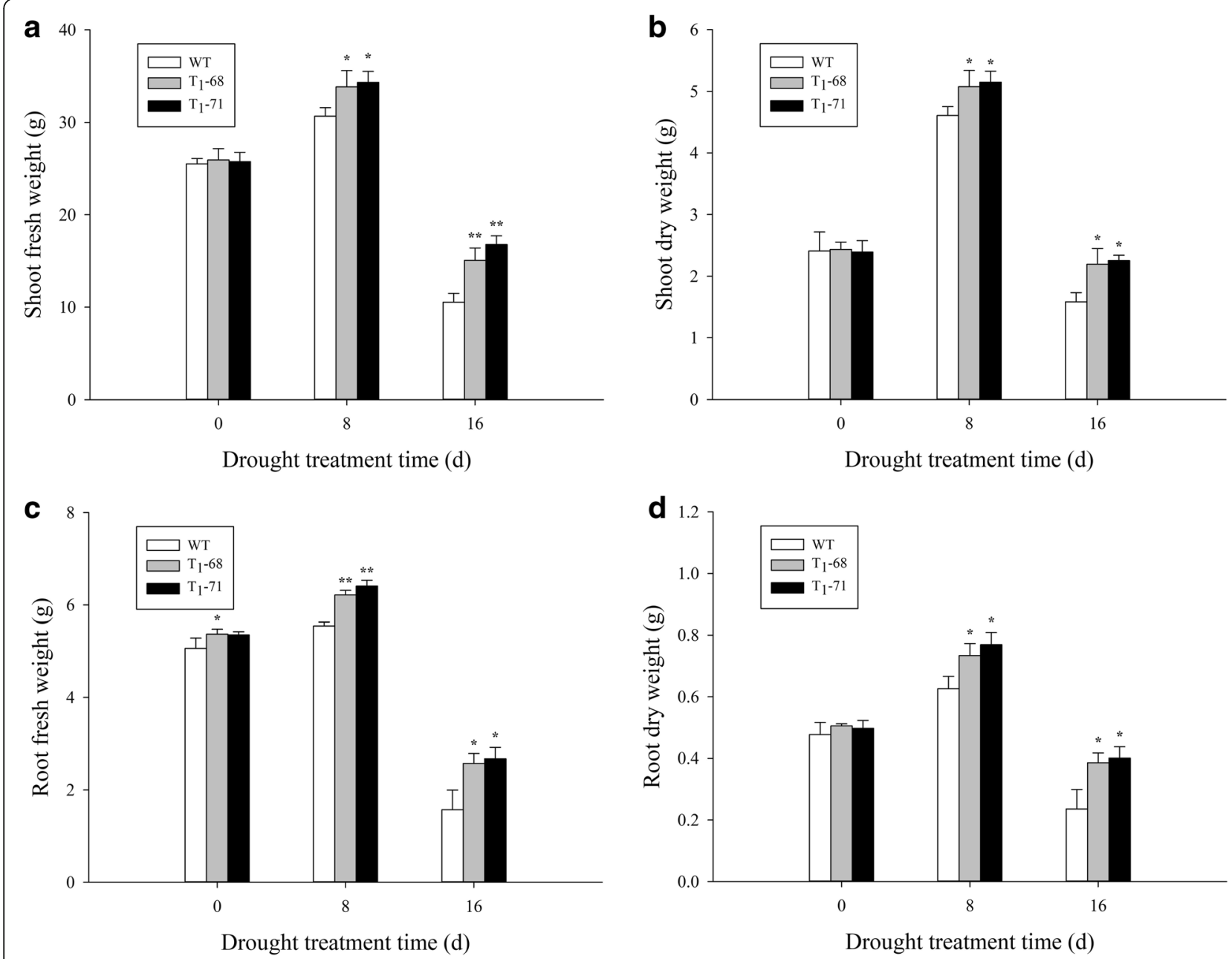

Fig. 4 Shoots and roots fresh weights $(\mathbf{a}, \mathbf{c})$ and dry weights $(\mathbf{b}, \mathbf{d})$ of wild type (WT) and transgenic tobacco seedlings were measured after drought stress treatment of 0,8 and $16 \mathrm{~d}$, separately. Values are means $\pm \operatorname{SD}(n=3) .{ }^{*}$ and ${ }^{*}$ Significant at $P<0.05$ and $P<0.01$ compared with WT, respectively

that of 0 day. These results indicated that the osmolytes were significantly upregulated by the CsPLD $\alpha$ regulation.

\section{CSPLDa expression improved tolerance to drought in tobacco}

The Fig. 7 showed that the CsPLD $\alpha$ overexpression in tobacco significantly enhanced the tolerance of seedlings to drougth stress after 0,8 , and 16 days of treatment (shoot in Fig. 7a, b, and c and root in Fig. 7f, g, and h). After 30 days of treatment, all lines exhibited severe wilting (Fig. 7d). However, after $2 \mathrm{~d}$ of re-watering, the transgenic lines recovered to grow, whereas the WT plants continued to wilt and died (Fig. 7e). The solute potential $(\Psi \mathrm{s})$ and RWC were determined to understand the higher tolerance of the transgenic plants to drought than the WT. The $\Psi$ s value was more negative in the transgenic plants than in the WT (Fig. 8a). This finding indicated that the transgenic plants possessed a greater potential to retain water than the WT plants. This result was verified by the RWC assay (Fig. $8 \mathrm{~b}$ ). After 8 days of drought stress, the RWC decreased by $16.9 \%$ in the WT plants but only by 11.1 and $11.3 \%$ in the ' $\mathrm{T}_{1}-68$ ' and ' $\mathrm{T}_{1}-71$ ', respectively. Similarly, after 16 days of drought stress, the RWC declined by $48.9 \%$ in the WT plants but only by 35.1 and $34.6 \%$ in ' $\mathrm{T}_{1}-68$ ' and ' $\mathrm{T}_{1}-71$ ', respectively. Therefore, the CsPLD $\alpha$ overexpression enhanced the capacity for osmotic adjustment and consequently increased the water retention during -the drought stress in the transgenic tobacco plants.

\section{Discussion}

This study showed that the CsPLD $\alpha$ overexpression exerted positive effects to the plant response to water deficit. When external water is lacking, the water inside the plant cell leaks to the outside of the cell, decreasing cell turgor pressure and changing the osmotic potential 

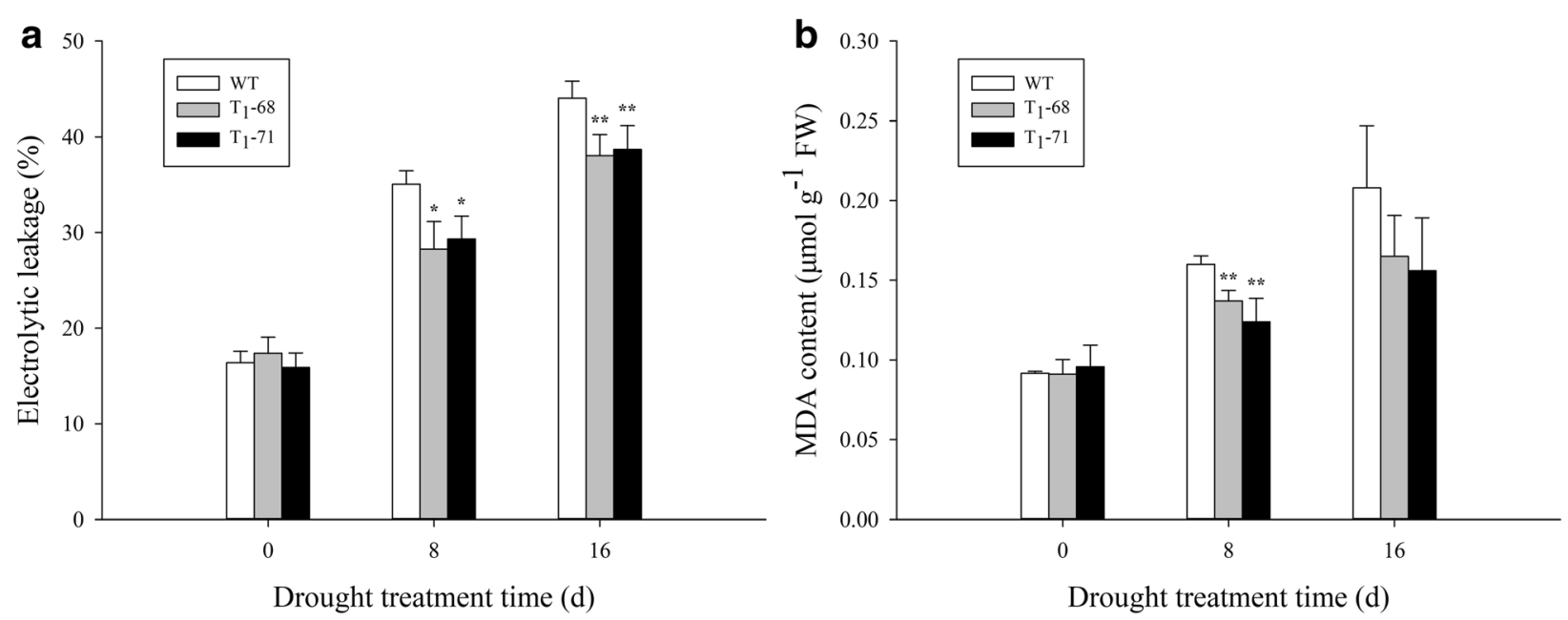

Fig. 5 Effects of drought stress on electrolytic leakage (EL) (a) and malondialdehyde (MDA) content (b) in leaves of both wild type (WT) and transgenic tobacco after treatment of 0,8 and $16 \mathrm{~d}$. Values are means $\pm \mathrm{SD}(n=3) .{ }^{*}$ and ${ }^{* *}$ Significant at $P<0.05$ and $P<0.01$ compared with WT, respectively

across the cell membrane. According to the osmosensor hypothesis, a change in osmotic potential leads to a structural change of the kind of protein in cell membranes called osmosensors; reduced hyperosmolality-induced $\left[\mathrm{Ca}^{2+}\right]_{i}$ increase 1 (OSCA1) may be an osmosensor in Arabidopsis and is induced by a stimulus in plants [35]. The main osmosensor in plants is a two-component system that includes histidine protein kinase and response regulator protein, and this system plays an important role in the rapid acceptance and transduction to osmotic signal $[36,37]$. Aquaporins, one of the most important types of transmembrane osmosensors, can change the structure across the membrane by sensing differences in extracellular water potential and transfer the water potential signal into other intracellular signaling molecules [38]. Through this process, the plant cell receives and conducts the drought signal through various pathways. The regulation of cell membrane lipid modification by phospholipase is one of the important pathways. Such modification can induce cells to produce different kinds of signaling molecules, such as PA, diacylglycerol (DAG), DAG-pyrophosphates, lysophosphatide, free fatty acids, and phosphatidylinositol [39-41].

PA plays an important role in the phospholipid signaling pathway and is mainly produced by phospholipase $C$ and PLD [42]. Water deficit can quickly activate PLD $[43,44]$, and the activated PLD is involved in ABA-mediated stomatal closure, which helps reduce transpiration and prevent water loss, meanwhile, maintains cell turgor pressure to against drought stress [28, 29]. PLD $\alpha 1$ and PA regulate ABA-induced stomatal closure by depolymerizing microtubules [45]. $P L D \delta$ is also involved in ABA-induced stomatal closure. $P L D \delta$ mRNA levels increase in response to severe dehydration [46], and its expression is upregulated by ABA in guard cells [47]. The interaction between PLD $\delta$ and glyceraldehyde-3-phosphate dehydrogenases in mediating plant response to $\mathrm{ABA}$ and water deficits has been well identified [48]. Zhang et al. [26] suggested that $P L D \alpha 1$ and $P L D \delta$ are involved in the same signaling pathway activated by ABA. However, Uraji and Murata [49] proposed that PLD 1 and $P L D \delta$ demonstrate a cooperative function in ABA-induced stomatal closure. Moreover, PLD 1 -deficient plants display delayed ABA-promoted leaf senescence [50]. In the current study, CsPLD $\alpha$ was overexpressed in the tobacco plants, and the synthesis and metabolism of ABA in both transgenic and WT tobacco under drought treatment were monitored. First, the expression of endogenous NtPLD 1 exhibited no difference between the WT and transgenic plants, and the expression of the drought-induced marker gene NtNAC072 was improved in the transgenic plants under drought stress (Fig. 1). This finding suggested that the CsPLD $\alpha$ overexpression could enhance the sensitivity of plants to drought stress. The expression of the ABA-related genes was affected, the most important one of which was NtNCED1, which is a rate-limiting enzyme in the ABA synthesis pathway. The NtNCED1 expression was up-regulated by drought stress and was higher in the transgenic plants than in the WT. The expression of NtAOG, which mediates ABA degradation, was lower in the transgenic plants than in the WT. Thus, the ABA content significantly accumulated in the transgenic plants (Fig. 2). A gene in the ABA synthetic pathway, NtSDR, was not affected by the drought signal (Fig. 2c), and the previous research has supported the same result [16]. Leaf stomatal closure 

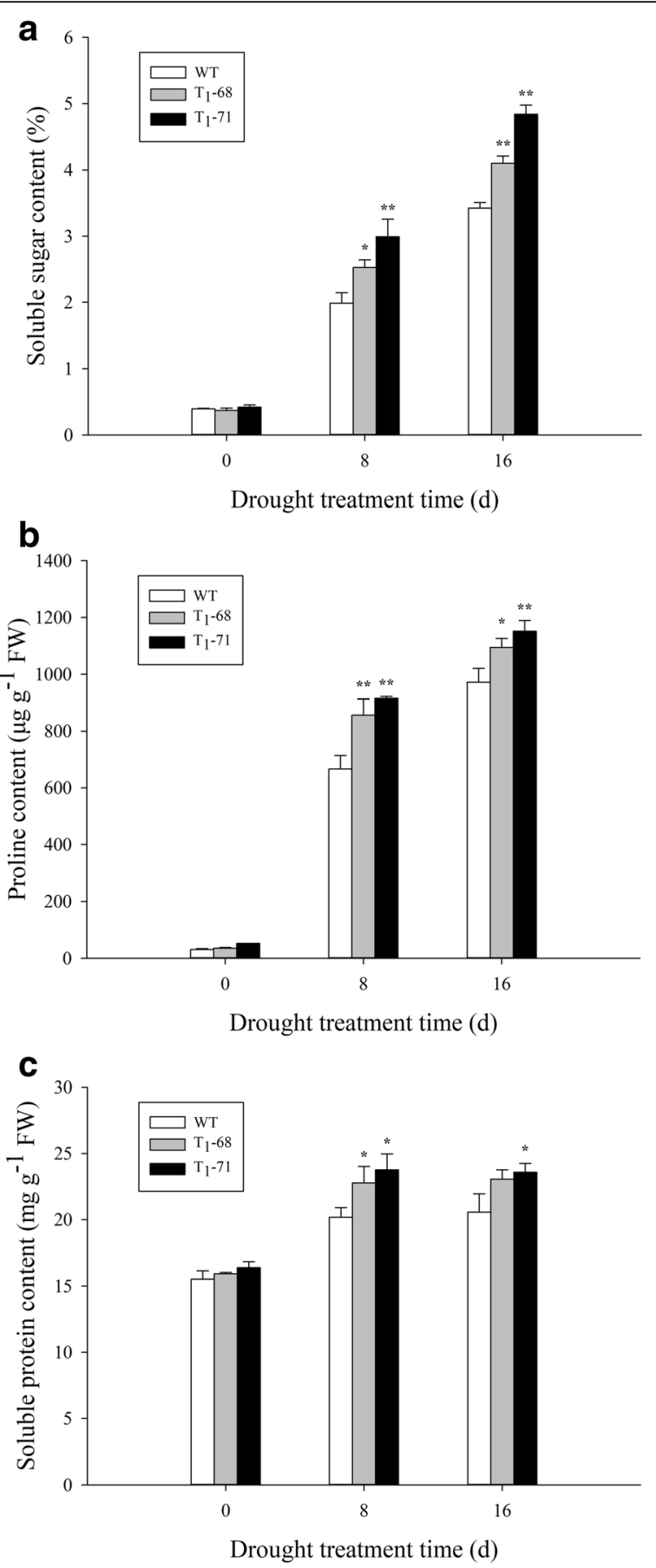

Fig. 6 Effects of drought stress on contents of soluble sugar (a), proline (b) and soluble protein (c) in leaves of both wild type (WT) and transgenic tobacco after treatment of 0,8 and $16 \mathrm{~d}$. Values are means $\pm \mathrm{SD}(n=3) .{ }^{*}$ and ${ }^{* *}$ Significant at $P<0.05$ and $P<0.01$ compared with WT, respectively

extent was also observed. The stomatal aperture width of the transgenic plants was less than that of the WT (Fig. 3b). Thus, the increased stomatal closure in the transgenic plants reduced the water loss in comparison with the WT and kept relatively high level water content [27]. The data on leaf water loss after a short water deficit (Fig. 3c) and leaf relative water content (Fig. 8b) after prolonged water deficit both supported this finding. These results indicated that CsPLD $\alpha$ was involved in the ABA-promoted stomatal closure during water deficit, further reduced the transpiration, and therefore enhanced the water retention.

Second, PA not only mediated the ABA-promoted stomatal closure to resist drought stress. In Arabidopsis, PLD can be used as a positive component to promote proline synthesis [51]. Proline is one of the most effective intracellular osmolytes; it can enhance water retention and maintain membrane structure stability and enzyme activity $[52,53]$. Therefore, proline content can directly or indirectly reflect the strength of the resistance of plants to osmotic stress. Other osmolytes maintain osmotic balance, including soluble sugar [54, 55] and glycine betaine [56]. Soluble sugar content is increased in enhanced ZmPLC1 expression in transgenic maize [57]. In the current study, the contents of proline, soluble sugar, and soluble protein in both the transgenic plants and WT accumulated rapidly and enhance the resistance to drought stress. However, in prolonged drought stress, the osmolyte content in the transgenic plant was more than that in the WT (Fig. 6); hence, the solute potential in the transgenic plant was less than that in the WT (Fig. 8a). These results showed that the CsPLD $\alpha$-driven PA could mediate the osmolyte synthesis to maintain the osmotic balance and alleviate the stress damage.

MDA is commonly used to indicate lipid peroxidation and increases in response to short-term drought stress $[58,59]$. EL is equally useful in stress [60]. PLD is also involved in membrane lipid remodeling and rearrangement, which contribute to the synthesis of other kinds of lipids under stress, especially in phosphorus deficit, to maintain the balance of membrane system structure and cell function [61-64]. In the current study, the MDA content and EL in the leaves of the transgenic plants were significantly lower than those of the WT (Fig. 5). This finding indicated that the overexpressed CsPLD $\alpha$ could reduce the damage of membrane lipid peroxidation, maintain the membrane system structure stability and function, and decrease the membrane ion leakage during water deficit.

On the basis of the present and previous results, we concluded that the tobacco seedlings with overexpressed CsPLD $\alpha$ exhibited improved resistance to water deficit. A schematic illustration for a possible mechanism of CsPLD $\alpha$ in plants is presented in Fig. 9. The main adaptive strategies to water deficit are the following: (1) $C s P L D \alpha$ and CsPLD $\alpha$-produced PA can decrease water loss by ABA-mediated stomatal closure, and (2) CsPLD $\alpha$ 


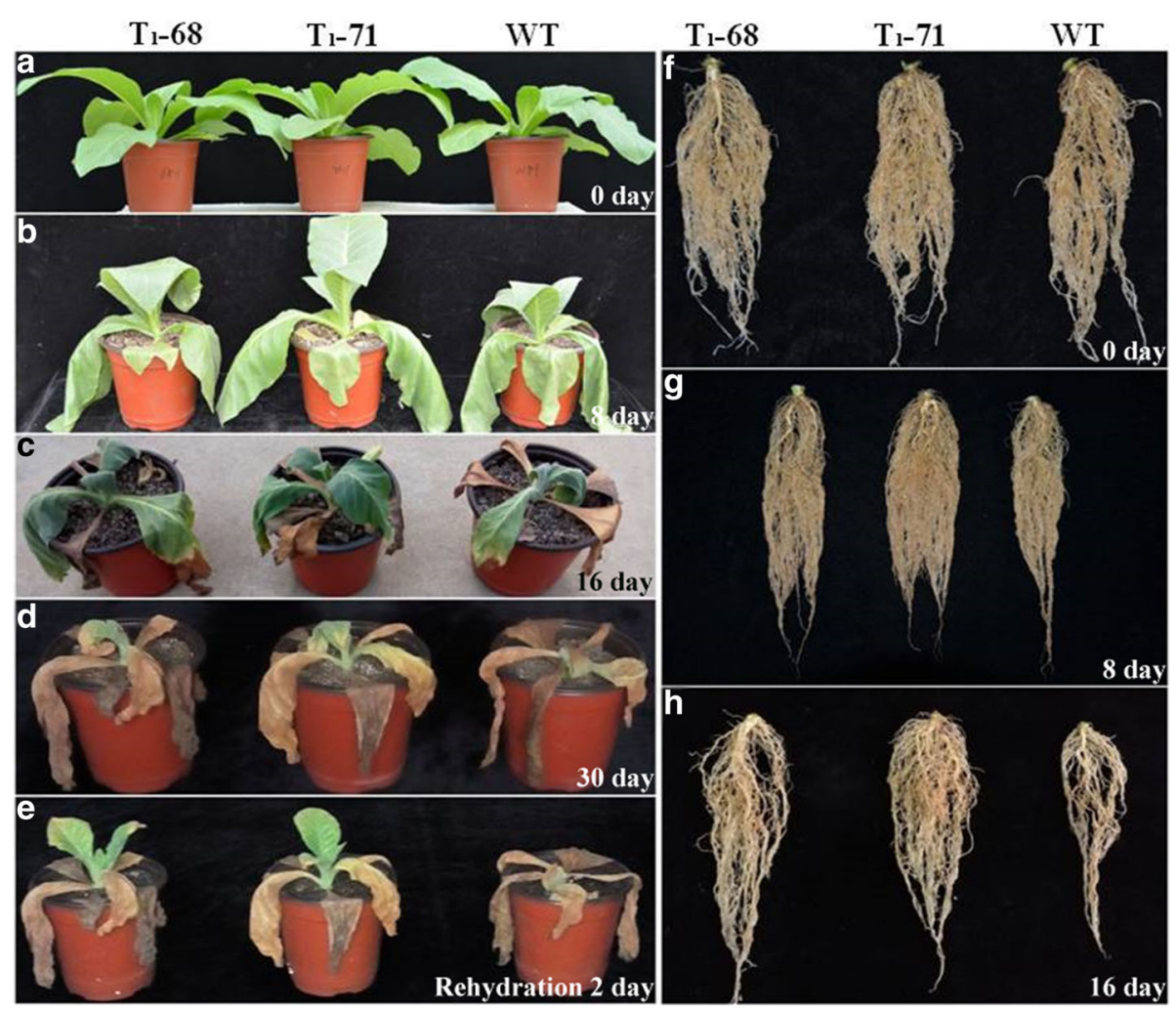

Fig. 7 Assessment of drought stress in wild type (WT) and transgenic tobacco seedlings and roots. Phenotypes of WT and transgenic seedlings and roots under conditions of control and drought stress. Photographs were taken after drought stress treatment of $0 \mathrm{~d}(\mathbf{a}, \mathbf{f}), 8 \mathrm{~d}(\mathbf{b}, \mathbf{g}), 16 \mathrm{~d}(\mathbf{c}$, h), $30 \mathrm{~d}$ (d) and seedlings (e) after refresh treatment of $2 \mathrm{~d}$

facilitates the accumulation of osmoprotective compounds to maintain osmotic balance and stabilize the membrane system. However, previous research showed that plants with overexpressed PLD 1 display increased susceptibility to drought stress under prolonged water deficit [21]. PA is not conducive to the stability of membrane system, and its presence can accelerate the formation of hexagonal $\mathrm{H}_{\text {II }}$ phase, break the membrane lipid bilayer structure, and destroy membrane integrity and cell function [65]. PA can be phosphorylated to
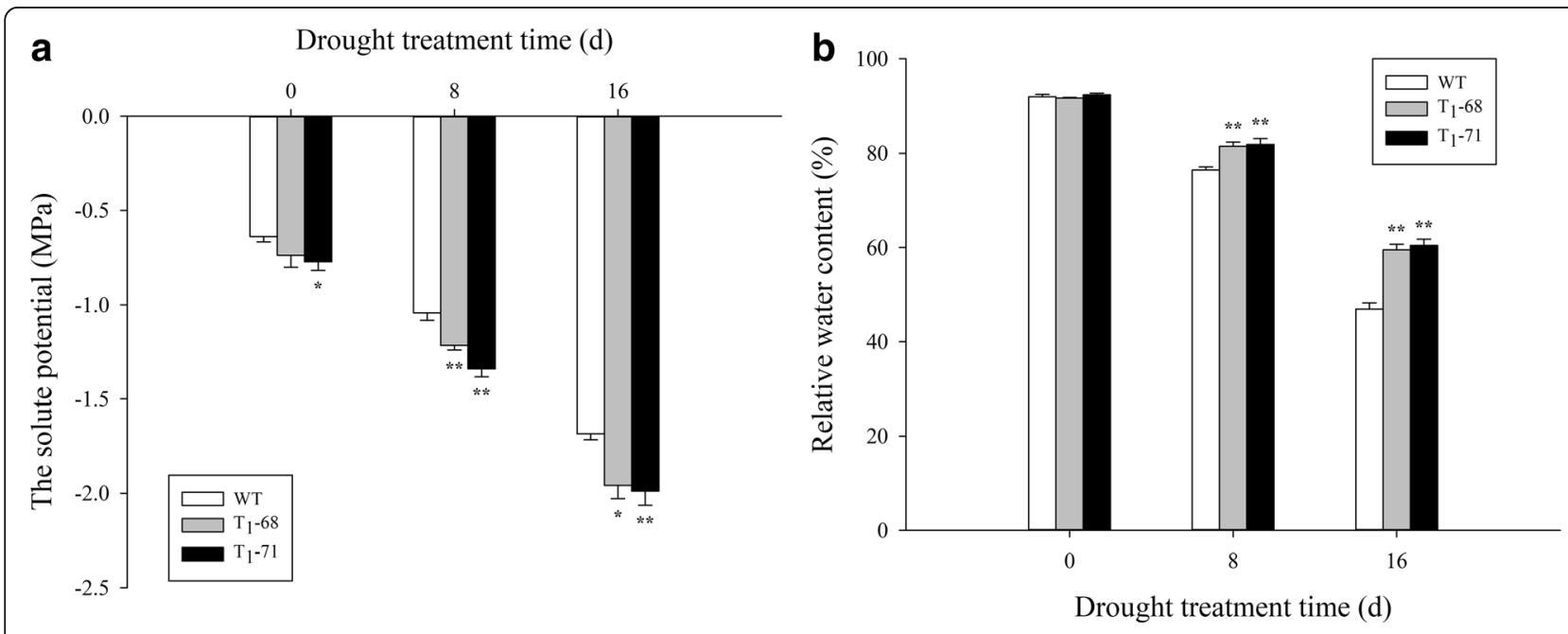

Fig. 8 Effects of drought stress on solute potential (a) and relative water content (RWC) (b) in leaves of both wild type (WT) and transgenic tobacco after treatment of 0,8 and $16 \mathrm{~d}$. Values are means $\pm \mathrm{SD}(n=3) .{ }^{*}$ and ${ }^{* *}$ Significant at $P<0.05$ and $P<0.01$ compared with WT, respectively 


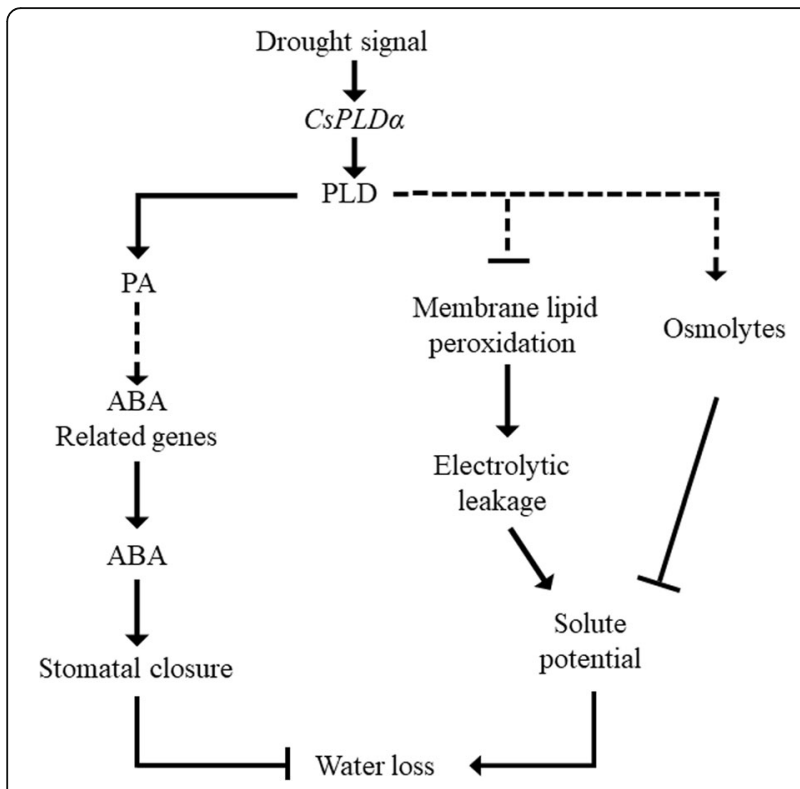

Fig. 9 Schematic illustration for main mechanism functioned by CSPLDa. 1) CsPLDa and CsPLDa-produced PA can mediate the stomatal closure by ABA synthesis and metabolism to reduce water loss; 2) CSPLDa facilitates the accumulation of osmolytes to reduce water loss; 3) and CSPLDa also stabilizes the membrane lipid balance to inhibit ion leakage which led to a higher solute potential and keeps water intracellular

pyrophosphate DAG, a new type of phospholipid [26]. These reactions may decrease the function of signal transduction. The identification of the upstream regulators and downstream targets that are involved in PLD signaling transduction in plant stress responses will be essential in unraveling the cross-talk between lipid signaling cascades and other signaling pathways. These findings revealed that the role of CsPLD $\alpha$ and PA in the regulatory mechanism of plant response to stress is extremely complex. Thus, further studies are needed to verify the interaction between these different functions.

\section{Conclusions}

Both overexpressed CsPLD $\alpha$ and it produced-PA are involved in controlling water loss by regulating more stomatal closure and the homeostasis of solute potential, therefore, CsPLD $\alpha$ is expressed dominantly in vigorously growing tobacco cells under drought stress, both in leaves and roots, and its overexpression plants can improve the tolerance to water deficit. These also indicated the role of CsPLD $\alpha$ in the regulating mechanism of plant response to drought stress is extremely complex, thus we still need further study to verify the interaction between all these different functions.

\section{Methods}

Plant materials, growth condition, and drought stress treatment

Tobacco (Nicotiana tabacum cv. NC89) was used for the assays as the wild type, and the transgenic lines ' $\mathrm{T}_{1}-68$ ' and ' $\mathrm{T}{ }_{1}-71$ ' resulting from self-fertilization were produced during a previous research [33]. Based on the previous study $[33,34]$, the WT seeds were sown 2 days earlier, and all seeds were sterilized and sown into plastic plots. Seedlings were grown in a controlled environment with an air temperature of $28^{\circ} \mathrm{C}$ (day)/ $23^{\circ} \mathrm{C}$ (night), a light intensity of $140 \mu \mathrm{mol} \mathrm{m}^{-2} \mathrm{~s}^{-1}$, and a relative humidity of $60 \%$. The four-week seedlings were transferred into a plastic plug filled with nursery substrate, and grew in glass greenhouse at Shandong Agricultural University. The plants were watered with a Hoagland complete nutrient solution just like describing at [34] before treatment and refreshment. The experiment was conducted under natural conditions with an air temperature of $25-30{ }^{\circ} \mathrm{C}$ during the day and $18-25^{\circ} \mathrm{C}$ at night. After 2 weeks, the young tobacco seedlings were used as experimental materials for the treatments. The drought stress treatment was performed according to the method described by Hong et al. [21]. The plugs were arranged in a completely randomized block design with 15 replicates per treatment. The tobacco plants were watered with the Hoagland nutrient solution the day prior to the treatment ( 0 day), and the watering was stopped in the succeeding 30 days. All lines were refreshed for 2 days. The samples were collected after 0,8 , and 16 days of treatments, and quantitative real-time PCR (RT-PCR) were performed. The $\mathrm{H}_{2} \mathrm{O}_{2}$ and ABA contents; plant fresh weight (FW) and dry weight (DW); electrolytic leakage (EL); malondialdehyde (MDA), proline, soluble sugar, and soluble protein contents; relative water content (RWC); and solute potential were measured in the leaves or roots.

\section{Stomatal closure and water loss determination}

To determine the percentage of closed stomata and stomatal aperture in response to dehydration, the leaves of the tobacco seedlings prior to the treatment were detached and exposed to an illuminated incubator with an air temperature of $23^{\circ} \mathrm{C}$ and a cool, white light intensity of $125 \mu \mathrm{mol} \mathrm{m}{ }^{-2} \mathrm{~s}^{-1}$. At $0,10,20$ and $30 \mathrm{~min}$ after detachment, the percentage of closed stomata and stomata aperture were determined using a scanning electron microscope (Japanese Electronics Co., Ltd.) and analyzed using the Image-Pro software. Each treatment in each genotype used 30 stomata. Water loss was determined after $0,0.5,1,3,5$, and $8 \mathrm{~h}$.

\section{Quantitative RT-PCR}

Total RNA was extracted from the leaves by using the TRIzol method in accordance to the manufacturer's 
instructions (CWBio), and the reverse transcription reaction was done by using the TransScript One-Step gDNA Removal and cDNA Synthesis SuperMix (TransGen). The primer sequences are shown in Additional file 1: Table S1. For the determination of drought stress-associated gene expression, the qRT-PCR was performed using the TransStart ${ }^{\circ}$ Tip Green qPCR SuperMix, and detected by using an ABI 7500 RT-PCR instrument (Thermo Fisher Scientific, USA), as described in the literature [66]. Each expression profile was independently verified in triplicate. Data were analyzed using the SDS 2.0 software (ABI), and the relative gene expression levels were calculated using the $2^{-\Delta \Delta \mathrm{Ct}}$ method [67].

\section{Extraction and determination of $A B A$ content}

The ABA extraction and determination were performed in accordance with the method of Cheng et al. [16] with modifications. Fresh samples $(0.5 \mathrm{~g})$ were homogenized and extracted, then incubated at $4{ }^{\circ} \mathrm{C}$. Phosphate buffer was added to the extract, and $1 \mathrm{ng}$ of ABA (SA8750, Beijing Solarbio Life Sciences, Beijing, China) was added to each sample as internal standard, in accordance with the method of Asami et al. [68]. After distilling the acetone, lipids were removed by partitioning the aqueous concentrate with hexanes. Then the aqueous phase was adjusted to a pH 2.5 and extracted using ethyl acetate. The acidic fraction was dried and dissolved in methanol. The solution was subjected to HPLC on a $\mu$ Bondapak C18 $(30 \mathrm{~cm} \times 0.78 \mathrm{~cm}$ column; Waters, Milford, MA, USA). The ABA was collected from $10.0 \mathrm{~min}$ to $12.0 \mathrm{~min}$. The fractions containing ABA were dried and methylated with diazomethane. The methylated ABA was used for the LC-MS analysis.

The LC-MS analysis was performed using a triple quadrupole liquid chromatography mass spectrometer (TSQ Quantum) with a DB-1 capillary column. The chromatographic conditions were as follows. Thermo Scientific Hypersil C18 column was used with mobile phases of methanol (B) and water (D). In the elution gradient, the mobile phase $\mathrm{B}$ was increased from 20 to $90 \%$ within $6 \mathrm{~min}$, maintained at $90 \%$ for $2 \mathrm{~min}$, and then decreased to $20 \%$ within 4 min. The velocity, column temperature, and sample quantity were 0.3 $\mathrm{ml} / \mathrm{min}, 30^{\circ} \mathrm{C}$, and $5 \mu \mathrm{l}$, respectively. The mass spectrometry conditions were as follows. The negative ion mode was utilized for electrospray power. The spray voltage, gasification temperature, sheath pressure, auxiliary air pressure, ion transport tube temperature, collision gas, and scanning mode were $3.5 \mathrm{kV}, 350^{\circ} \mathrm{C}$, 35 arb, 15 arb, $350^{\circ} \mathrm{C}, 1.5 \mathrm{mTor}$, and SRM, respectively.

\section{Determination of plant FW and DW}

Under the stress conditions after 0,8 , and 16 days of treatment, three plants each from the WT, ' $\mathrm{T}_{1}-68$ ', and ' $\mathrm{T}_{1}-71$ ' were collected. The FWs of tobacco were measured immediately. The samples were dried at $80^{\circ} \mathrm{C}$ for $48 \mathrm{~h}$, and then the DWs were measured.

\section{EL and lipid peroxidation analysis}

The EL and MDA content were determined in accordance with the method of Wang et al. [69] with modifications. Leaves were sampled at 0,8 , and 16 days after treatment and washed with deionized water. The membrane ion leakage was expressed as the percentage of initial conductivity versus total conductivity. The MDA content was expressed as the nonspecific absorbance at $600 \mathrm{~nm}$ was subtracted from the absorbance at $532 \mathrm{~nm}$, and the difference was used to calculate the amount of MDA by using an extinction coefficient of $155 \mathrm{mM}^{-1}$ $\mathrm{cm}^{-1}[70]$.

\section{Determination of proline, soluble sugar, and soluble protein contents}

Proline extraction was used an improved sulfo-salicylic acid method which described by $\mathrm{Xu}$ et al. [71]. The soluble sugar was determined by using sulfuric acidanthrone colorimetry [72]. The protein content determination was based on Bradford [73].

\section{RWC determination}

The FWs of the tobacco leaves were measured immediately after detachment from the seedlings. The turgor weight was determined after incubation in deionized water overnight, and the leaf samples were dried at $80^{\circ} \mathrm{C}$ for $48 \mathrm{~h}$ to obtain the DW. The RWC was calculated based on the following equation: RWC $(\%)=(\mathrm{FW}-\mathrm{DW}) /(\mathrm{TW}-\mathrm{DW}) \times 100[20]$.

\section{Measurement of solute potential}

The solute potential $(\Psi \mathrm{s})$ was measured as described by Gaxiola et al. [74]. The osmotic potential was determined using a vapor pressure osmometer (model 5520, Wescor, USA). $\Psi \mathrm{s}=-$ moles of solute $(R \times K)$, where $R=$ 0.008314 and $K=293^{\circ}$.

\section{Statistical analyses}

Values were presented as means \pm standard deviations of the triplicates. Statistical analyses were conducted using ANOVA with SAS (SAS Institute, Cary, NC, USA). Differences between treatments were separated by the least significant difference test at $P<0.05$ and $P<0.01$. 


\section{Additional file}

Additional file 1: Table S1. Primers for real-time quantitative PCR. (DOCX $16 \mathrm{~kb}$ )

\section{Abbreviations}

ABA: Abscisic acid; $\mathrm{CO}_{2}$ : Carbon dioxide; DAG: Diacylglycerol; DW: Dry weight; EDTA: Ethylenediaminetetraacetic acid; EL: Electrolytic leakage; FW: Fresh weight; LC-MS: Liquid chromatography mass spectrometer; MDA: Malondialdehyde; NADPH: Nicotinamide adenine dinucleotide phosphate [H]; NO: Nitric Oxide; OE: Overexpression; PA: Phosphatidic acid; PLD: Phospholipase D; qRT-PCR: Quantitative real-time polymerase chain reaction; ROS: Reactive oxygen species; RWC: Relative water content; WT: Wild type

\section{Acknowledgements \\ Not applicable.}

\section{Funding}

This work was supported by National Natural Sciences Foundations of China (NO.31372060, NO.30900983), Collaborative Innovation Center of Fruit \& Vegetable Quality and Efficient Production in Shandong, the China Agriculture Research System (CARS-25-D) and Collaborative Innovation Center of Protected Vegetable Suround Bohai Gulf Region. This article is supported by the Foundation of Shandong Provincial Young Teachers' Development Plan. All these funding play roles in the design of the study and collection, analysis, and in writing the manuscript.

\section{Availability of data and materials}

The datasets used and/or analysed during the current study available from the corresponding author on reasonable request.

\section{Authors' contributions}

Conceived and designed the research: FY, SL, and TJ. Performed the research and analyzed the data: SL and TJ. LL contributed to the qRT-PCR assay and participated in other assays. MH contributed to the acquisition of transgenic lines. XW, MW, QS made key comments on the design of the trial, the article writing, and the revisions. YL and BG contributed to the improvement of the method, which including plant growth condition, stomatal closure and ABA content determination. Wrote the first draft of the manuscript: TJ. Improved the first draft of the manuscript: FY and SL. All authors have read and approved this manuscript.

\section{Ethics approval and consent to participate}

The plant materials (including seeds) performed in the current study were complied with institutional, national and international guidelines. All of our researches were conducted in our laboratories and greenhouses at Shandong Agricultural University (Tai'an, China). No specific permits were required.

\section{Consent for publication}

Not applicable.

\section{Competing interests}

The authors declare that they have no competing interests.

\section{Publisher's Note}

Springer Nature remains neutral with regard to jurisdictional claims in published maps and institutional affiliations.

Received: 12 March 2018 Accepted: 6 December 2018

Published online: 14 December 2018

\section{References}

1. Reddy AR, Chaitanya KV, Vivekanandan M. Drought-induced responses of photosynthesis and antioxidant metabolism in higher plants. Plant Physiol. 2004;161(11):1189-202. https://doi.org/10.1016/j.jplph.2004.01.013.

2. dos Reis SP, Marques DN, Lima AM, de Souza CRB. Plant molecular adaptations and strategies under drought stress. In: Hossain M, Wani S,
Bhattacharjee S, Burritt D, Tran LS. (eds) Drought Stress Tolerance in Plants, Vol 2. Cham: Springer; 2016. https://doi.org/10.1007/978-3-319-32423-4_4.

3. Xie Q, Gong Z. Understanding abiotic stresses and the solution. J Integr Plant Biol. 2008;50(10):1185-6. https://doi.org/10.1111/j.1744-7909.2008.00774.x.

4. Pottosin I, Shabala S. Polyamines control of cation transport across plant membranes: implications for ion homeostasis and abiotic stress signaling. Front Plant Sci. 2014;5(3):154. https://doi.org/10.3389/fpls.2014.00154.

5. Jammes F, Song C, Shin D, Munemasa S, Takeda K, Gu D, Cho D, Lee S, Giordo R, Sritubtim S, Leonhardt N, Ellis BE, Murata Y, Kwak JM. MAP kinases MPK9 and MPK12 are preferentially expressed in guard cells and positively regulate ROS-mediated ABA signaling. PNAS. 2009;106(48):20520-5. https:// doi.org/10.1073/pnas.0907205106.

6. Zhu JK. Salt and drought stress signal transduction in plants. Annu Rev Plant Biol. 2002;53:247-73. https://doi.org/10.1146/annurev.arplant.53. 091401.143329.

7. Krasensky J, Jonak C. Drought, salt, and temperature stress-induced metabolic rearrangements and regulatory networks. J Exp Bot. 2012;63(4): 1593-608. https://doi.org/10.1093/jxb/err460.

8. Nahar K, Hasanuzzaman M, Alam MM, Fujita M. Glutathione-induced drought stress tolerance in mung bean: coordinated roles of the antioxidant defense and methylglyoxal detoxification systems. Aob Plants. 2015;7(1):plv069. https://doi.org/10.1093/aobpla/plv069.

9. Chrispeels MJ, Holuigue L, Latorre R, Luan S, Orellana A, Peña-Cortes H, Raikhel NV, Ronald PC, Trewavas A. Signal transduction networks and the biology of plant cells. Biol Res. 1999;32(1):35-60.

10. Lindemose S, O'Shea C, Jensen M, Skriver K. Structure, function and networks of transcription factors involved in abiotic stress responses. IJMS. 2013;14(3):5842. https://doi.org/10.3390/ijms14035842.

11. Todaka D, Shinozaki K, Yamaguchishinozaki K. Recent advances in the dissection of drought-stress regulatory networks and strategies for development of drought-tolerant transgenic rice plants. Front Plant Sci. 2015:6(84):84. https://doi.org/10.3389/fpls.2015.00084.

12. Shinozaki K, Yamaguchi-Shinozaki K. Molecular responses to dehydration and low temperature: differences and cross-talk between two stress signaling pathways. Curr Opin Plant Biol. 2000;3(3):217-23.

13. Taji T. Regulation of drought tolerance by gene manipulation of 9-cisepoxycarotenoid dioxygenase, a key enzyme in abscisic acid biosynthesis in Arabidopsis. Plant J. 2001:27(4):325-33.

14. Nambara E, Marion-Poll A. Abscisic acid biosynthesis and catabolism. Annu Rev Plant Biol. 2005:56:165-85. https://doi.org/10.1146/annurev.arplant.56.032604. 144046.

15. Welsch R, Wüst F, Bär C, Albabili S, Beyer P. A third phytoene synthase is devoted to abiotic stress-induced abscisic acid formation in rice and defines functional diversification of phytoene synthase genes. Plant Physiol. 2008; 147(1):367-80. https://doi.org/10.1104/pp.108.117028.

16. Cheng WH, Endo A, Zhou L, Penney J, Chen HC, Arroyo A, Leon P, Nambara E, Asami T, Seo M, Koshiba T, Sheen J. A unique short-chain dehydrogenase/reductase in Arabidopsis glucose signaling and abscisic acid biosynthesis and functions. Plant Cell. 2002:14(11):2723-43.

17. McAinsh MR, Brownlee C, Hetherington AM. Abscisic scid-induced elevation of guard cell cytosolic $\mathrm{Ca}^{2+}$ precedes Stomatal closure. Nature. 1990;343(6254):186

18. Montillet JL, Leonhardt N, Mondy S, Tranchimand S, Rumeau D, Boudsoca M, Garcia AV, Douki T, Bigeard J, Laurière C, Chevalier A, Castresana C, Hirt H. An abscisic acid-independent oxylipin pathway controls stomatal closure and immune defense in Arabidopsis. PLoS Biol. 2013;11(3):e1001513. https:// doi.org/10.1371/journal.pbio.1001513.

19. Kim TH, Böhmer M, Hu H, Nishimura N, Schroeder Jl. Guard cell signal transduction network: advances in understanding abscisic acid, $\mathrm{CO}_{2}$, and $\mathrm{Ca}^{2+}$ signaling. Annu Rev Plant Biol. 2010;61:561-91. https://doi.org/10.1146/ annurev-arplant-042809-112226.

20. Hong $Y$, Pan $X$, Welti $R$, Wang $X$. Phospholipase Da3 is involved in the hyperosmotic response in Arabidopsis. Plant Cell. 2008;20(3):803-16. https:// doi.org/10.1105/tpc.107.056390.

21. Hong $Y$, Zheng $S$, Wang $X$. Dual functions of phospholipase Da1 in plant response to drought. Mol Plant. 2008;1(2):262-9. https://doi.org/10.1093/ $\mathrm{mp} / \mathrm{ssm} 025$

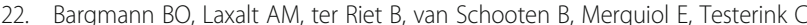
Haring MA, Bartels D, Munnik T. Multiple PLDs required for high salinity and water deficit tolerance in plants. Plant Cell Physiol. 2009:50:78-89. https:// doi.org/10.1093/pcp/pcn173. 
23. Lu S, Bahn SC, Qu G, Qin H, Hong Y, Xu Q, Zhou Y, Hong Y, Wang X. Increased expression of phospholipase Dalpha1 in guard cells decreases water loss with improved seed production under drought in Brassica napus. Plant Biotechnol J. 2013;11:380-9. https://doi.org/10.1111/pbi. 12028.

24. Frank W, Bartels D. Water deficit triggers phospholipase D activity in the resurrection plant Craterostigma plantagineum. Plant Cell. 2000;12(1):111-23.

25. Munnik T, Meijer HJG, Ter Riet B, Hirt H, Frank W, Bartels D, Musgrave A. Hyperosmotic stress stimulates phospholipase D activity and elevates the levels of phosphatidic acid and diacylglycerol pyrophosphate. Plant J. 2000; 22(2):147-54

26. Zhang W, Yu L, Zhang Y, et al. Phospholipase D in the signaling networks of plant response to abscisic acid and reactive oxygen species[J]. Biochim Biophys Acta. 2005;1736(1):1-9. https://doi.org/10.1016/j.bbalip.2005.07.004

27. Huang GT, Ma SL, Bai LP, Zhang L, Ma H, Jia P, Liu J, Zhong M, Guo ZF. Signal transduction during cold, salt, and drought stresses in plants. Mol Biol Rep. 2012;39(2):969-87. https://doi.org/10.1007/s11033-011-0823-1.

28. Zhang W, Qin C, Zhao J, Wang X. Phospholipase Da1-derived phosphatidic acid interacts with $\mathrm{AB} 11$ phosphatase $2 \mathrm{C}$ and regulates abscisic acid signaling. PNAS. 2004;101(25):9508-13. https://doi.org/10.1073/pnas. 0402112101.

29. Mishra G, Zhang W, Deng F, Zhao J, Wang X. A bifurcating pathway directs abscisic acid effects on stomatal closure and opening in Arabidopsis. Science. 2006;312(5771):264-6. https://doi.org/10.1126/science.1123769.

30. Sang Y, Zheng S, Li W, Huang B, Wang X. Regulation of plant water loss by manipulating the expression of phospholipase Da. Plant J. 2001;28(2):135-44.

31. Zhao J, Wang X. Arabidopsis phospholipase Da1 interacts with the heterotrimeric g-protein $a$-subunit through a motif analogous to the dry motif in g-protein-coupled receptors. J Biol Chem. 2004;279(3):1794-800 https://doi.org/10.1074/jbc.M309529200.

32. Zhang $Y$, Zhu H, Zhang Q, Li M, Yan M, Wang R, Wang L, Welti R, Zhang W, Wang $X$. Phospholipase Da1 and phosphatidic acid regulate NADPH oxidase activity and production of reactive oxygen species in ABA-mediated stomatal closure in Arabidopsis. Plant Cell. 2009;21(8): 2357-77. https://doi.org/10.1105/tpc.108.062992.

33. Li S, Huang M, Di Q, Ji T, Wang X, Wei M, Shi Q, Li Y, Gong B, Yang F. The functions of a cucumber phospholipase D alpha gene (CSPLDa) in growth and tolerance to hyperosmotic stress. Plant Physiol Biochem. 2015;97:17586. https://doi.org/10.1016/j.plaphy.2015.10.006.

34. Ji T, Li S, Huang M, Di Q, Wang X, Wei M, Shi Q, Li Y, Gong B, Yang F. Overexpression of cucumber phospholipase D alpha gene (CSPLDa) in tobacco enhanced salinity stress tolerance by regulating $\mathrm{Na}^{+}-\mathrm{K}^{+}$balance and lipid peroxidation. Front Plant Sci. 2017;8:499. https://doi.org/10.3389/ fpls.2017.00499.

35. Yuan F. OSCA1 mediates osmotic-stress-evoked $\mathrm{Ca}^{2+}$ increases vital for osmosensing in Arabidopsis. Nature. 2014;514(7522):367-71. https://doi.org/ 10.1038/nature13593.

36. West AH, Stock AM. Histidine kinases and response regulator proteins in two-component signaling systems. Trends Biochem Sci. 2001;26(6):369.

37. Chang C, Stewart RC. The two-component system: regulation of diverse signaling pathways in prokaryotes and eukaryotes. Plant Physiol. 1998; 117(3):723-31.

38. Hill AE, Shachar-Hill Y. Are aquaporins the missing transmembrane osmosensors? J Membr Biol. 2015;248(4):753-65. https://doi.org/10.1007/ s00232-015-9790-0.

39. Wang X. Lipid signaling. Curr Opin Plant Biol. 2004;7(3):329-36. https://doi. org/10.1016/j.pbi.2004.03.012.

40. Bargmann BOR, Munnik T. The role of phospholipase D in plant stress responses. Curr Opin Plant Biol. 2006;9(5):515-22. https://doi.org/10.1016/j. pbi.2006.07.011.

41. Boss WF, Lynch DV, Wang X. Lipid-Mediated Signaling. Annual Plant Reviews volume 33: Intracellular Signaling in Plants; 2009. p. 202-43.

42. Pleskot R, Li J, Žárský V, Potocký M, Staiger CJ. Regulation of cytoskeletal dynamics by phospholipase D and phosphatidic acid. Trends Plant Sci. 2013;18(9):496-504. https://doi.org/10.1016/j.tplants.2013.04.005.

43. Distéfano AM, Valinas MA, Scuffi D, Lamattina L, Ten Have A, GarcíaMata C, Laxalt AM. Phospholipase D $\delta$ knock-out mutants are tolerant to severe drought stress. Plant Signal Behav. 2015;10(11):e1089371. https://doi.org/10.1080/15592324.2015.1089371.

44. Wang J, Ding B, Guo Y, Li M, Chen S, Huang G, Xie X. Overexpression of a wheat phospholipase D gene, TaPLDa, enhances tolerance to drought and osmotic stress in Arabidopsis thaliana. Planta. 2014;240(1):103-15. https://doi org/10.1007/s00425-014-2066-6

45. Jiang Y, Wu K, Lin F, Qu Y, Liu X, Zhang Q. Phosphatidic acid integrates calcium signaling and microtubule dynamics into regulating ABA-induced stomatal closure in Arabidopsis. Planta. 2014;239(3):565-75. https://doi.org/ 10.1007/s00425-013-1999-5.

46. Katagiri T, Takahashi S, Shinozaki K. Involvement of a novel Arabidopsis phospholipase D, AtPLD $\delta$, in dehydration-inducible accumulation of phosphatidic acid in stress signalling. Plant J. 2001;26(6):595-605.

47. Distéfano AM, Scuffi D, García-Mata C, Lamattina L, Laxalt AM. Phospholipase D $\delta$ is involved in nitric oxide-induced stomatal closure. Planta. 2012;236(6):1899-907. https://doi.org/10.1007/s00425-012-1745-4.

48. Guo L, Devaiah SP, Narasimhan R, Pan X, Zhang Y, Zhang W, Wang X. Cytosolic glyceraldehyde-3-phosphate dehydrogenases interact with phospholipase D $\delta$ to transduce hydrogen peroxide signals in the Arabidopsis response to stress. Plant Cell. 2012;24(5):2200-12. https://doi.org/10.1105/tpc.111.094946.

49. Uraji M, Murata Y. Cooperative function of PLD $\delta$ and PLDa1 in abscisic acidinduced stomatal closure in Arabidopsis. Plant Physiol. 2012;159(1):450-60. https://doi.org/10.1104/pp.112.195578.

50. Fan L, Zheng S, Wang X. Antisense suppression of phospholipase Da retards abscisic acid-and ethylene-promoted senescence of postharvest Arabidopsis leaves. Plant Cell. 1997;9(12):2183-96.

51. Ghars MA, Richard L, Lefebvre-De Vos D, Leprince AS, Parre E, Bordenave M, Abdelly C, Savoure A. Phospholipases C and D modulate proline accumulation in thellungiella halophila/salsuginea differently according to the severity of salt or hyperosmotic stress. Plant Cell Physiol. 2012;53:18392. https://doi.org/10.1093/pcp/pcr164.

52. Yang SL, Lan SS, Gong M. Hydrogen peroxide-induced proline and metabolic pathway of its accumulation in maize seedlings. J Plant Physiol. 2009:166(15):1694-9. https://doi.org/10.1016/j.jplph.2009.04.006.

53. Verbruggen $N$, Hermans $C$. Proline accumulation in plants: a review. Amino Acids. 2008:35:753-9. https://doi.org/10.1007/s00726-008-0061-6.

54. Vinocur B, Altman A. Recent advances in engineering plant tolerance to abiotic stress: achievements and limitations. Curr Opin Biotech. 2005;16(2): 123-32. https://doi.org/10.1016/j.copbio.2005.02.001.

55. Da Silva JM, Arrabaca MC. Contributions of soluble carbohydrates to the osmotic adjustment in the C4 grass Setaria sphacelata: a comparison between rapidly and slowly imposed water stress. J Plant Physiol. 2004;161:551-5.

56. Ashraf M, Foolad MR. Roles of glycine betaine and proline in improving plant abiotic stress resistance. Environ Exp Bot. 2007:59:206-16. https://doi. org/10.1016/j.envexpbot.2005.12.006.

57. Wang CR, Yang AF, Yue GD, Gao Q, Yin HY, Zhang JR. Enhanced expression of phospholipase C 1 ( $\mathrm{mPLC1}$ ) improves drought tolerance in transgenic maize. Planta. 2008;227(5):1127-40. https://doi.org/10.1007/s00425-007-0686-9.

58. Weber $H$, Chételat A, Reymond P, Farmer EE. Selective and powerful stress gene expression in Arabidopsis in response to malondialdehyd. Plant J. 2004:37(6):877-88

59. Alam MM, Hasanuzzaman M, Nahar K, Fujita M. Exogenous salicylic acid ameliorates short-term drought stress in mustard (Brassica juncea L) seedlings by up-regulating the antioxidant defense and glyoxalase system. Aust J Crop Sci. 2013;7(7):1053-63.

60. Demidchik V, Yurin V. Stress-induced electrolyte leakage: the role of $\mathrm{K}^{+}$permeable channels and involvement in programmed cell death and metabolic adjustment. J Exp Bot. 2014;65(5):1259-70. https://doi.org/10. 1093/jxb/eru004.

61. Gigon A, Matos AR, Laffray D, Zuily-Fodil Y, Pham-Thi AT. Effect of drought stress on lipid metabolism in the leaves of Arabidopsis thaliana (ecotype Columbia). Ann Bot. 2004;94(3):345-51. https://doi.org/10.1093/aob/mch150.

62. Cruz-Ramírez A, Oropeza-Aburto A, Razo-Hernández F, Ramírez-Chávez E, Herrera-Estrella L. Phospholipase DZ2 plays an important role in extraplastidic galactolipid biosynthesis and phosphate recycling in Arabidopsis roots. PANS. 2006;103:6765-70. https://doi.org/10.1073/pnas.0600863103.

63. Li M, Welti R, Wang X. Quantitative profiling of Arabidopsis polar glycerolipids in response to phosphorus starvation: roles of phospholipases D zeta1 and D zeta2 in phosphatidylcholine hydrolysis and digalactosyldiacylglycerol accumulation in phosphorus -starved plants. Plant Physiol. 2006;142:750-61. https://doi.org/10.1104/pp.106.085647.

64. Tjellstrom H, Andersson MX, Larsson KE, Sandelius AS. Membrane phospholipids as a phosphate reserve: the dynamic nature of phospholipidto-digalactosyl diacylglycerol exchange in higher plants. Plant Cell Environ. 2008;31:1388-98. https://doi.org/10.1111/j.1365-3040.2008.01851.x. 
65. Verkleij A, De Maagd R, Leunissen-Bijvelt J, De Kruijff B. Divalent cations and chlorpromazine can induce non-bilayer structures in phosphatidic acidcontaining model membranes. BBA-Biomembranes. 1982;684:255-62.

66. Li Q, Wang XF, Ma LY, Wei M, Shi QH, Yang FJ. Molecular characterization of a cucumber nitrate reductase (CsNR) gene under $\mathrm{NO}_{3}{ }^{-}$stress. Mol Biol Rep. 2012;39:4283-90. https://doi.org/10.1007/s11033-011-1215-2.

67. Livak KJ, Schmittgen TD. Analysis of relative gene expression data using real-time quantitative PR and the $2^{-\Delta \Delta C T}$ method. Methods. 2001;25(4): 402-8.

68. Asami T, Sekimata K, Wang JM, Yoneyama K, Takeuchi Y, Yoshida S. Preparation of $( \pm)-\left[1,2-{ }^{13} \mathrm{C}_{2}\right]$ abscisic acid for use as a stable and pure internal standard. Chem. 1999;31(7):658-9. https://doi.org/10.1002/chin. 200007160.

69. Wang H, Liang X, Huang J, Zhang D, Lu H, Liu Z, Bi Y. Involvement of ethylene and hydrogen peroxide in induction of alternative respiratory pathway in salt-treated Arabidopsis calluses. Plant Cell Physiol. 2010;51: 1754-65. https://doi.org/10.1093/pcp/pcq134.

70. Larkindale J, Huang B. Effects of abscisic acid, salicylic acid, ethylene and hydrogen peroxide in thermotolerance and recovery for creeping bentgrass. Plant Growth Regul. 2005;47(1):17-28.

71. Xu HN, Sun XD, Wang X, Shi QH, Yang XY, Yang FJ. Involvement of a cucumber MAPK gene (CSNMAPK) in positive regulation of ROS scavengence and osmotic adjustment under salt stress. Sci Hortic. 2011;127: 488-93. https://doi.org/10.1016/.scienta.2010.11.013.

72. Dubois M, Gilles K, Hamilton JK, Rebers PA, Smith F. A colorimetric method for the determination of sugars. Nature. 1951:168(4265):167.

73. Bradford MM. A rapid and sensitive method for the quantitation of microgram quantities of protein utilizing the principle of protein-dye binding. Anal Biochem. 1976;72(1-2):248-54.

74. Gaxiola RA, Li J, Undurraga S, Dang LM, Allen GJ, Alper SL, Fink GR. Drought- and salt tolerant plants result from overexpression of the AVP1 $H^{+}$-pump. PNAS. 2001;98:11444-9. https://doi.org/10.1073/pnas.191389398.

Ready to submit your research? Choose BMC and benefit from:

- fast, convenient online submission

- thorough peer review by experienced researchers in your field

- rapid publication on acceptance

- support for research data, including large and complex data types

- gold Open Access which fosters wider collaboration and increased citations

- maximum visibility for your research: over $100 \mathrm{M}$ website views per year

At $\mathrm{BMC}$, research is always in progress.

Learn more biomedcentral.com/submissions 